Available online at http://jifnp.tp.ugm.ac.id
INDONESIAN FOOD AND NUTRITION PROCRESS

Indonesian Food and Nutrition Progress, 2014, Vol. 13, Issue 1

\title{
Synthesis and Characterization of Hydroxypropylcellulose from Oil Palm Empty Fruit Bunches (Elaeis guineensis Jacq)
}

\author{
Djagal W. Marseno ${ }^{{ }^{*}}{ }$, Pepita Haryanti $^{2)}$, Binardo Adiseno ${ }^{3)}$, Haryadi $^{1)}$ \\ 1) Department of Food and Agricultural Product Technology, Faculty of Agricultural Technology, \\ Universitas Gadjah Mada, Yogyakarta 55281 - Indonesia. \\ ${ }^{2)}$ Department of Agricultural Product Technology, Faculty of Agricultural, \\ Jenderal Sudirman University. Purwokerto - Indonesia. \\ ${ }^{3)}$ Alumni of Study Program Magister of Estate Crop Technology, Faculty of Agricultural Technology, \\ Universitas Gadjah Mada, Yogyakarta 55281 - Indonesia. \\ *) Corresponding author. Tel./Fax. : 62-274-589797. E-mail: djagal@ugm.ac.id
}

Received 5 June 2014; Accepted 18 August 2014; Published Online 10 September 2014

\begin{abstract}
Indonesia has a lot of oil palm empty fruit bunches (EFB) and usually discarded as agricultural waste. The major component of this oil palm EFB is cellulose, which is useful for food industry in the form of cellulose derivatives such as hydroxypropylcellulose (HPC). This paper reported about a method to prepare HPC from oil palm EFB as cellulose source. Oil palm EFB was dried, cut and milled to obtain EFB powder passed from 60 mesh screen. Cellulose in the EFB powder was extracted using $4 \% \mathrm{NaOH}$ at $100 \circ \mathrm{C}$ for $3.5 \mathrm{~h}$, and then bleached using $5 \% \mathrm{NaOCl}$ at 30 ㅇ C for $3 \mathrm{~h}$. HPC was synthesized from cellulose using $\mathrm{NaOH}$ at $5-25 \%$ at $25 \circ \mathrm{C}$ for $1 \mathrm{~h}$, then propylene oxide (PO) at 0.6-1.4 $\mathrm{mL}$ per g cellulose was added to the slurry and the temperature was adjusted to 55을 for $3 \mathrm{~h}$. HPC from EFB cellulose had more less characters than its commercial especially in purity level. Alkalization using $10 \% \mathrm{NaOH}$ and its etherification using $1.4 \%(\mathrm{v} / \mathrm{w})$ PO gave HPC with the highest molar substitution (MS), viscosity, purity and crystallinity i.e. $0.1049 ; 76.88 \mathrm{cps} ; 76.91 \%$ and $24.39 \%$, respectively.
\end{abstract}

Keywords: cellulose, hydroxypropyl cellulose, oil palm empty fruit bunches

\section{Introduction}

In 2008, Indonesia is the largest crude palm oil producer and having the largest palm oil plantation in the world. Oil palm empty fruit bunches (EFB) is solid waste derived from process of extraction of crude palm oil (CPO) from fresh fruits bunches (FFB). From 1 ton of FFB will produced $22-23 \% \mathrm{EFB}$, that containing lignocellulosic materials having cellulose $(45,95 \%)$, hemicellulose $(22,84 \%)$, lignin $(16,49 \%)$, and ash (1,23\%) (Darnoko, 1992; Rahman et al., 2007). Oil palm EFB Cellulose is the predominant polymer in lignocellulosic material, having a linear homopolymer of anhydroglucose units linked together by $\beta-1.4$ glucosidic bonds (Imeson, 1999; Foyle et al., 2007). However, due to its inter- and intra-molecular hydrogen bonds, cellulose neither melts nor dissolves readily in common solvents (Imeson, 1999; Hattori et al., 2004).

In order to utilize cellulose in food industry, cellulose must be converted to its derivatives such as carboxymethyl cellulose (CMC) or hydroxypropylcellulose (HPC). Some methods to isolate and modify cellulose from agricultural products have been developed by many researcher (Adinugraha et al., 2005; Barai et al., 1997; Ramos et al., 2005; Yasar et al., 2007).

HPC is prepared by reacting alkali cellulose with propylene oxide (PO) in addition with inert diluents such as isopropanol. When alkylene oxides are used as reactants, new hydroxyl substituent groups that can further react are 
formed, and chaining out is possible. The extent of derivation is measured as the molar substitution (MS), where MS is defined as the average number of moles of substituent groups per anhydroglucose unit (Imeson, 1999). HPC is used for its emulsifying and thickening properties. It is soluble in water below $40^{\circ} \mathrm{C}$ and in many polar organic solvent e.g. methyl alcohol, ethyl alcohol, isopropyl alcohol (Mezdour et al., 2006).

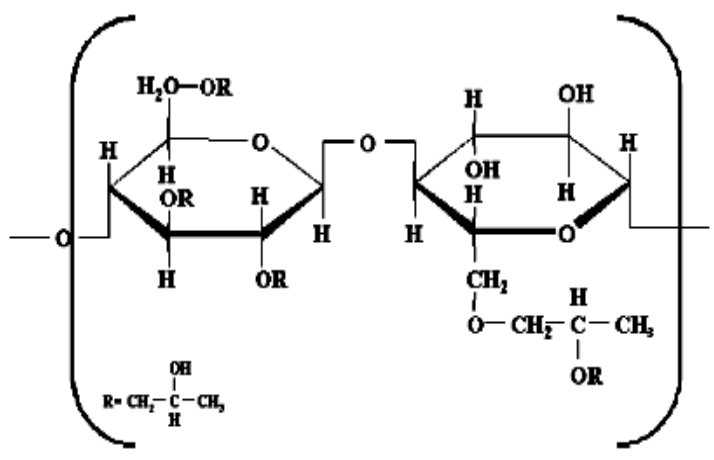

Fig. 1. Structure of a repeating unit of Hydroxypropylmethylcellulose (HPC). (Mezdour, 2006)

An idealized structure for the repeated unit of HPC molecule is given in Fig. 1. Hydroxyl groups in cellulose, usually replaced by hydroxypropyl groups in the order of $\mathrm{C}_{2}>\mathrm{C}_{6}>\mathrm{C}_{3}$ (Ho and Klosiewicz, 1980; Reuben and Conner, 1983; Tezuka, et al., 1996; Coffey et al., 1995). The objectives of this research were to develop a method of utilizing EFB as a resource of cellulose and modify its structure to hydroxypropyl cellulose (HPC).

\section{Materials and Methods}

Extraction of Cellulose from Oil Palm Empty Fruit Bunches (EFB)

EFB was obtained from a plantation in Riau Province - Indonesia. The obtained EFB was dried, cut into small pieces $( \pm 1 \mathrm{~cm})$ then milled for resulting EFB powder. The powder was passed through 60 mesh sieve. Basically, the Cellulose from EFB powder was extracted using our previous method (Adinugraha et al., 2005) with slight modification. Cellulose in the EFB powder was extracted in $4 \% \mathrm{NaOH}$ (based on optimization study) at ratio of EFB powder to $\mathrm{NaOH}$ solution was $1: 20(\mathrm{w} / \mathrm{v})$ for $3.5 \mathrm{~h}$ at $100^{\circ} \mathrm{C}$. The obtained black slurry was filtrated and washed using distilled water and bleached with $5 \% \mathrm{NaOCl}$ for 3 $\mathrm{h}$ at $30^{\circ} \mathrm{C}$. The bleached cellulose was washed again until the odor of hypochlorite could no longer be detected, then dried at $60^{\circ} \mathrm{C}$ in a cabinet dryer.

\section{Synthesis of Hydroxypropylcellulose (HPC)}

The cellulose powder was alkalized at $25^{\circ} \mathrm{C}$ for $1 \mathrm{~h}$ in a shaking waterbath with $4 \mathrm{~mL} / \mathrm{g}$ of various concentration of $\mathrm{NaOH}(5,10,15,20$ and $25 \%$ ) in $20 \mathrm{~mL} / \mathrm{g}$ of isopropanol as a solvent. After the alkalization process is over, various amount of propylene oxide (PO) 0.6, 0.8, 1.0, 1.2 and $1.4 \mathrm{~mL}$ per $\mathrm{g}$ cellulose was added and the temperature raised to $55^{\circ} \mathrm{C}$ and the reaction continued for $3 \mathrm{~h}$. The slurry was neutralized with $90 \%$ of acetic acid and then filtrated. The solid obtained as HPC was washed by $70 \%$ ethanol for four times to remove undesirable by products. The obtained cellulose derivative (HPC) was dried at $60^{\circ} \mathrm{C}$ in an cabinet dryer.

\section{Characterization of Hydroxypropyl Cellulose (HPC)}

The molar substitution is determined by FAO \& WHO (2001). While the moisture content, viscosity and purity of HPC were determined by the ASTM D 1439-94 standard method (ASTM, 1994).

\section{X-ray Diffraction and FT-IR Spectroscopy of HPC

A shimadzu XRD-6000 X-ray

diffractometer was operated at $\mathrm{Cu} \mathrm{K} \alpha$ wavelength of $1.54 \AA$ A, $30 \mathrm{~mA}$ and $40 \mathrm{kV}$. The crystallinity of cellulose was calculated using the method from Wakida et al., (2002).

Infrared spectra of the HPC samples were recorded with Shimadzu FTIR-8201 PC. Pellets were made from HPC samples ( 3 $\mathrm{mg}$ ) ground with $\mathrm{KBr}(\sim 800 \mathrm{mg})$. Transmission was measured at the wave number range of $4000-400 \mathrm{~cm}^{-1}$.

\section{Result and Discussion}

The obtained MS from this work was in the range of $0.0020-0.1049$, while according to Maruyama and Umezawa (2003), HPC for food applications and pharmaeutical was in the range 0.1- 0.5. The effect when the MS is below 0.1 it must be difficult to obtain the optimal water binding. The effect of $\mathrm{NaOH}$ and $\mathrm{PO}$ levels to the MS of HPC are shown in Table 1.

As shown on Table 1, the MS of HPC increased with increase in PO level especially at 5 and $10 \%$ of $\mathrm{NaOH}$. The highest MS was obtained at $10 \%$ concentration of $\mathrm{NaOH}$ with $\mathrm{PO} 1.4 \mathrm{~mL} / \mathrm{g}$. 
Table 1. Effect of various concentration of aqueous solutions of $\mathrm{NaOH}$ and amount of $\mathrm{PO}$ to the molar substitution of HPC made from EFB cellulose.

\begin{tabular}{|c|c|c|c|c|c|c|}
\hline \multirow{2}{*}{$\begin{array}{c}\text { Propylene } \\
\text { oxide } \\
\text { (mL/g) }\end{array}$} & \multicolumn{6}{|c|}{$\begin{array}{c}\text { Molar substitution (MS) } \\
\mathrm{NaOH}(\%)\end{array}$} \\
\hline & 5 & 10 & 15 & 20 & 25 & Mean \\
\hline 0,6 & $0.0059^{a b}$ & $0.0196^{\text {bcdef }}$ & $0.0243^{\text {cdefg }}$ & $0.0484^{\text {hi }}$ & $0.0020^{a}$ & $0.0200^{x}$ \\
\hline 0,8 & $0.0021^{a}$ & $0.0369^{\mathrm{gh}}$ & $0.0247^{\text {cdefg }}$ & $0.0567^{\mathrm{ij}}$ & $0.0142^{a b c d}$ & $0.0269^{y}$ \\
\hline 1,0 & $0.0051^{a b}$ & $0.0593^{\mathrm{ij}}$ & $0.0269^{\text {cdefg }}$ & $0.0303^{\text {defg }}$ & $0.0136^{a b c}$ & $0.0270^{y}$ \\
\hline 1,2 & $0.0133^{a b c}$ & $0.0581^{i j}$ & $0.0474^{\mathrm{hi}}$ & $0.0308^{\text {efg }}$ & $0.0150^{\text {abcde }}$ & $0.0329^{y}$ \\
\hline 1,4 & $0.0317^{\mathrm{fg}}$ & $0.1049^{k}$ & $0.0716^{j}$ & $0.0160^{\text {abcdef }}$ & $0.0207^{\text {bcdefg }}$ & $0.0490^{2}$ \\
\hline Mean & $0.0116^{p}$ & $0.0557^{q}$ & $0.0390^{r}$ & $0.0364^{r}$ & $0.0131^{p}$ & \\
\hline
\end{tabular}

Note: Nominal were followed by the same words showed that they were not different for significant level of $95 \%$. The average of nominal were followed by the same words in the line showed that they were not different for significant level of $95 \%$. The average of nominal were followed by the same words in the column showed that they were not different for significant level of $95 \%$.

Table 2. Effect of various concentration of aqueous solutions of $\mathrm{NaOH}$ and amount of $\mathrm{PO}$ to the purity level of $\mathrm{HPC}$ made from EFB cellulose.

\begin{tabular}{|c|c|c|c|c|c|c|}
\hline \multirow{2}{*}{$\begin{array}{c}\text { Propylene } \\
\text { oxide } \\
\text { (mL/g) }\end{array}$} & \multicolumn{6}{|c|}{$\begin{array}{c}\text { Purity level (\%) } \\
\mathrm{NaOH}(\%)\end{array}$} \\
\hline & 5 & 10 & 15 & 20 & 25 & Mean \\
\hline 0,6 & $89.16^{\text {ef }}$ & $91.59^{f}$ & $84.85^{\text {bcdef }}$ & $74.30^{a}$ & $80.34^{\text {abcde }}$ & $84.05^{Y}$ \\
\hline 0,8 & $86.85^{\text {cdef }}$ & $92.24^{f}$ & $88.78^{\text {ef }}$ & $82.48^{\text {abcdef }}$ & $78.93^{\mathrm{abcd}}$ & $85.85^{Y}$ \\
\hline 1,0 & $88.23^{\text {def }}$ & $82.95^{\text {abcdef }}$ & $85.43^{\text {bcdef }}$ & $83.69^{\text {abcdef }}$ & $79.48^{\text {abcde }}$ & $83.95^{Y}$ \\
\hline 1,2 & $86.36^{\text {bcdef }}$ & $86.95^{\text {cdef }}$ & $86.66^{\text {bcdef }}$ & $80.64^{\text {abcde }}$ & $74.48^{a}$ & $83.02^{Y}$ \\
\hline 1,4 & $82.96^{\text {abcdef }}$ & $76.91^{\mathrm{ab}}$ & $77.17^{\mathrm{abc}}$ & $81.49^{\text {abcde }}$ & $77.10^{a b c}$ & $79.13^{x}$ \\
\hline Mean & $86.71^{q}$ & $86.13^{q}$ & $84.58^{q}$ & $80.52^{p}$ & $78.07^{p}$ & \\
\hline
\end{tabular}

Note: Nominal were followed by the same words showed that they were not different for significant level of $95 \%$. The average of nominal were followed by the same words in the line showed that they were not different for significant level of $95 \%$. The average of nominal were followed by the same words in the column showed that they were not different for significant level of $95 \%$.

Table 3. Effect of various concentration of aqueous solutions of $\mathrm{NaOH}$ and amount of $\mathrm{PO}$ to the viscosity of HPC made from EFB cellulose

\begin{tabular}{|c|c|c|c|c|c|c|}
\hline \multirow{2}{*}{$\begin{array}{c}\text { Propylene } \\
\text { oxide } \\
\text { (ml/g) }\end{array}$} & \multicolumn{6}{|c|}{$\begin{array}{c}\text { Viscosity (cps) } \\
\mathrm{NaOH}(\%)\end{array}$} \\
\hline & 5 & 10 & 15 & 20 & 25 & Mean \\
\hline 0,6 & $54.38^{a b}$ & $63.75^{\text {defg }}$ & $65.63^{\text {efgh }}$ & $70.63^{\mathrm{ijk} k}$ & $51.88^{a}$ & $61.25^{x}$ \\
\hline 0,8 & $51.25^{a}$ & $69.38^{\text {hijk }}$ & $66.25^{\text {fghi }}$ & $73.75^{I m n}$ & $62.50^{\text {def }}$ & $64.63^{Y}$ \\
\hline 1,0 & $52.50^{a}$ & $71.88^{\mathrm{klm}}$ & $66.88^{\text {ghij }}$ & $68.75^{\text {hijk }}$ & $61.87^{\text {cde }}$ & $64.38^{Y}$ \\
\hline 1,2 & $58.13^{b c}$ & $74.38^{\mathrm{Imn}}$ & $71.25^{\mathrm{jkl}}$ & $68.13^{\text {hijk }}$ & $61.25^{c d}$ & $66.63^{z}$ \\
\hline 1,4 & $69.38^{\text {hijk }}$ & $76.88^{n}$ & $75.63^{\mathrm{mn}}$ & $63.13^{\text {defg }}$ & $53.13^{a}$ & $67.63^{z}$ \\
\hline Mean & $57.13^{p}$ & $71.25^{r}$ & $69.13^{q}$ & $68.88^{q}$ & $58.13^{p}$ & \\
\hline
\end{tabular}

Note: Nominal were followed by the same words showed that they were not different for significant level of $95 \%$. The average of nominal were followed by the same words in the line showed that they were not different for significant level of $95 \%$. The average of nominal were followed by the same words in the column showed that they were not different for significant level of $95 \%$ 
This is due to the greater level of PO in the proximity of cellulose molecules. However at high concentration of $\mathrm{NaOH}$, the increasing level of $\mathrm{PO}$ could not increase MS value, but the declining of MS was observed. This was likely due to the polymer degradation was occurred due to high concentration of $\mathrm{NaOH}$. At the low level of PO $(0.6$ and $0.8 \mathrm{~mL}$ ) per $\mathrm{g}$ cellulose and $\mathrm{NaOH}$ concentration below $10 \%$, low MS were obtained. These phenomena might be occurred due to limited amount of PO available for substituting cellulose and the $\mathrm{NaOH}$ concentration was not adequate to complete the conversion of cellulose to alkali cellulose. The declining of MS at higher concentration of $\mathrm{NaOH}(10 \%)$ could also be due to degradation of HPC polymers. The highest MS of HPC from this work was 0.1049 and synthesized using $10 \%$ of $\mathrm{NaOH}$ and $1.4 \mathrm{~mL}$ PO per g cellulose. The effect of $\mathrm{NaOH}$ concentration and $\mathrm{PO}$ amount to the purity of HPC are shown in Table 2.

It could be seen that at the same level of $\mathrm{PO}$ with increasing $\mathrm{NaOH}$ concentration (above $10 \%$ ), the purity of obtained HPC decreased (Table 2). The increasing level of PO also could not increase the purity level almost at all concentration of $\mathrm{NaOH}$. The $\alpha$-cellulose content in EFB cellulose that used in this work was only $79.83 \%(\mathrm{db})$. The impurities that have reactive hydroxyl groups could react with PO. It made possible that etherification agent reacted with those impurities.

From Table 3, it is obvious that etherification at the low concentration of $\mathrm{NaOH}$ $(5 \%)$, the increasing level of PO could not increased the viscosity of resulted HPC. But, at higher concentration of $\mathrm{NaOH}(10 \%)$ the increasing level of $\mathrm{PO}$ could increase the viscosity of HPC, but furthermore lowered the viscosity. In this work, viscosity was measured in $1 \%(\mathrm{w} / \mathrm{v})$ in water at $29 \circ \mathrm{C}$. The decrease of viscosity might be because of the degradation of HPC polymer especially at higher concentration of $\mathrm{NaOH}(>10 \%)$. If the polymer chain of HPC is shortened, the HPC is easier to dissolve in the water. At low concentration of $\mathrm{NaOH}$ with low level of $\mathrm{PO}$, low viscosity of HPC solution was observed. This probably, the MS of HPC was low, that the ability of HPC to immobilize water was reduced owning to the lack of hydrophylic groups.

The relationship between MS and viscosity could be plotted as a linear curve to show the effect of increase of MS to higher the viscosity of HPC solution (Fig. 2). Surely this was due to more hydroxypropyl groups substituted the hydroxyl groups of cellulose polymers. These hydroxypropyl groups act as hydrophyllic groups, therefore with the increase of MS, thus improved the ability of HPC to immobilize water in a system.

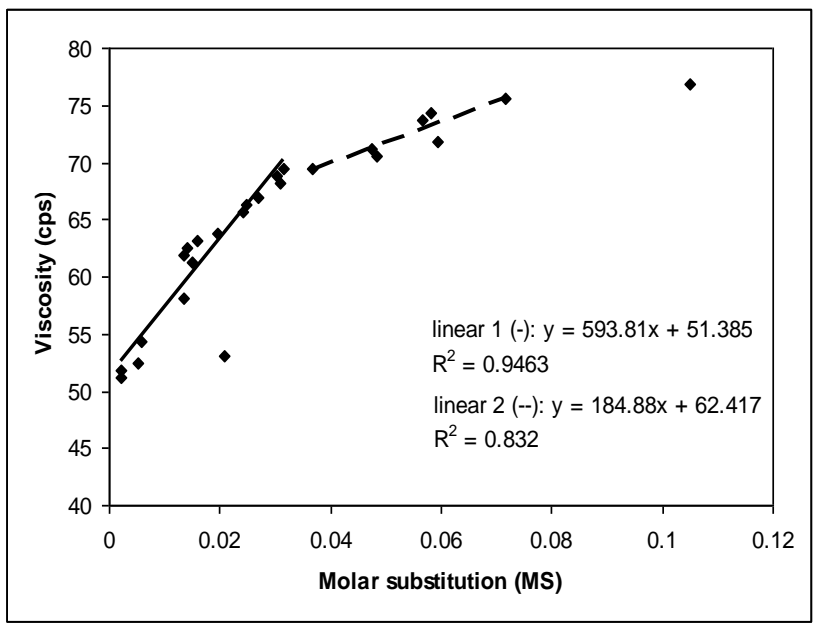

Fig. 2. Relationship between MS and viscosity of HPC made from EFB cellulose

The infrared spectroscopy spectra of HPC with MS 0.1049 was shown in Fig. 4. The peaks at wave number of 2924.09 and $1334.74 \mathrm{~cm}^{-1}$ indicated of the presence of hydroxypropyl substituent. According to Dean (1985) and Sastrohamidjojo (2007), methyl groups have wave number about 1450-1375 $\mathrm{cm}^{-1}$, while alkane groups (C-H stretch) have wave number 2850$3000 \mathrm{~cm}^{-1}$. The infrared spectroscopy spectra in Fig. 3 was similar to that shown in Fig. 4, but no peaks at some wave number like at spectra in Fig 3. Some unknown peaks at spectra in Fig. 4 were supposed to the contamination from impurities.

It is obvious that after alkalization process with $10 \% \mathrm{NaOH}$, the crystallinity of native EFB cellulose was reduced (Fig. 3). The crystallinity of native EFB cellulose and EFB cellulose after alkalization treatment were 39.13 and $31.67 \%$, respectively. The crystallinity of cellulose was associated with inter- and intra-molecular hydrogen bond of cellulose. According to Foyle et al., (2007), hydrogen bonding between cellulose molecules results in the formation of highly ordered crystalline regions that are not readily accessible to water.

The decrease of crystallinity when the cellulose was treated with $10 \% \mathrm{NaOH}$ was due to the cleavage of hydrogen bonds because of $\mathrm{NaOH}$. From Fig. 5, it is also shown that cellulose I was 


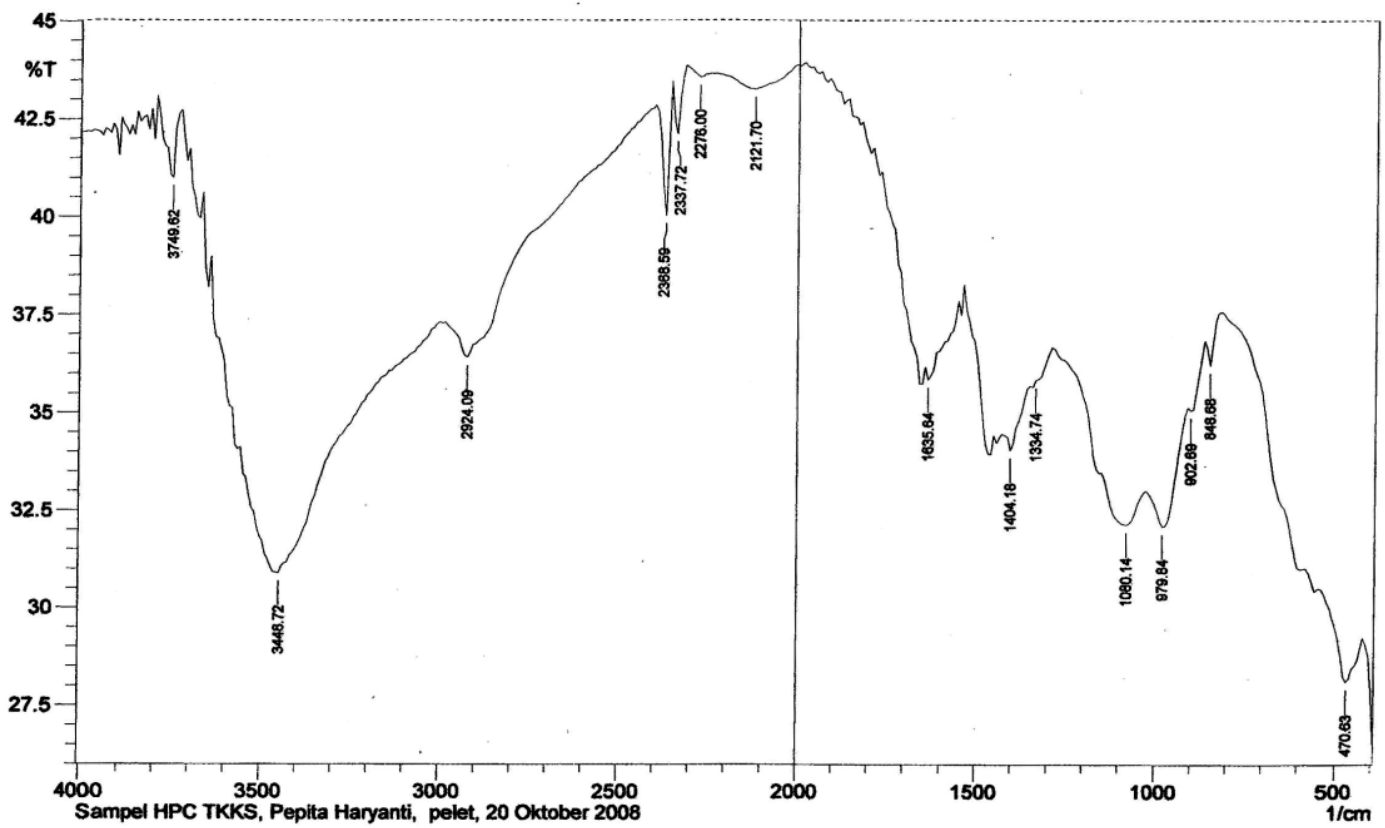

Fig. 3. FTIR spectra of HPC made from EFB cellulose with MS 0.1049 which was synthesized using $10 \% \mathrm{NaOH}$ and $1.4 \mathrm{ml}$ of $\mathrm{PO} / \mathrm{g}$ cellulose

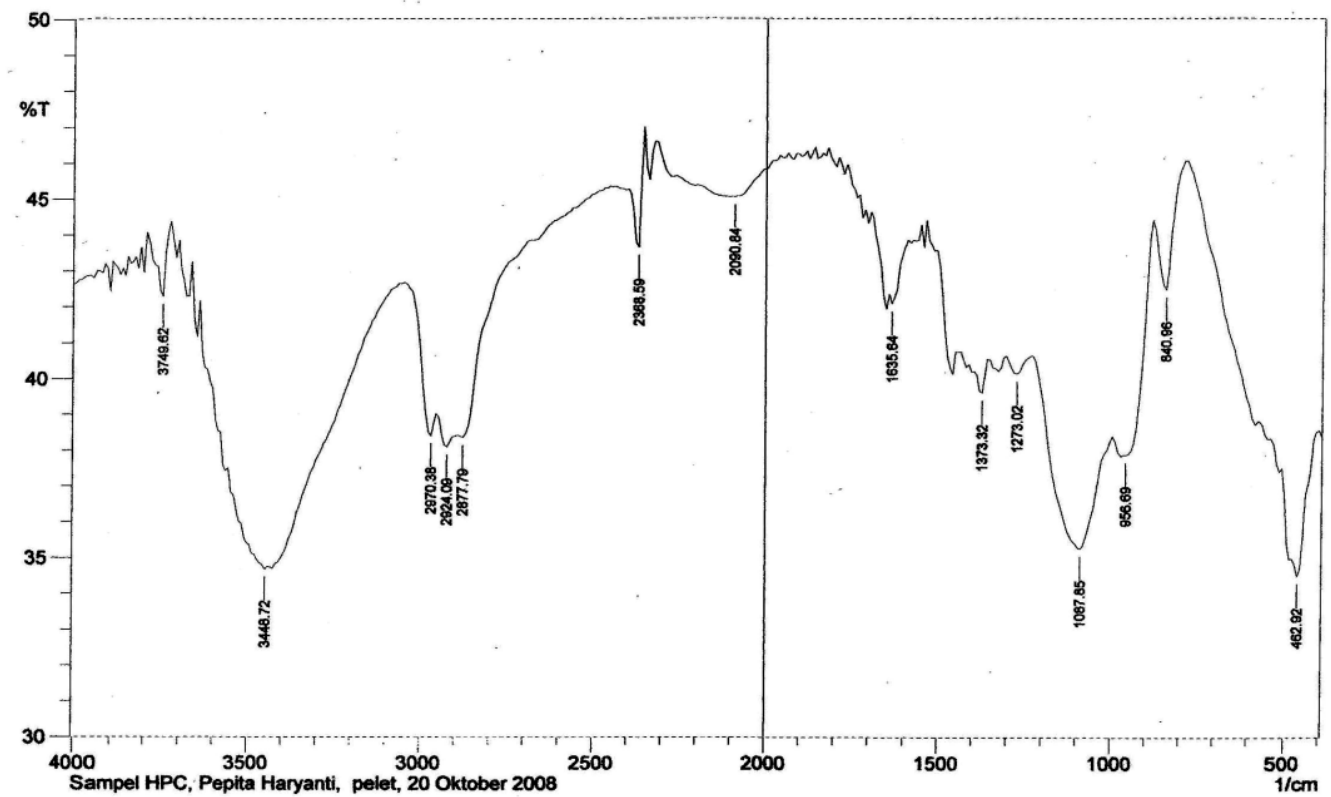

Fig. 4. FTIR spectra of commercial HPC (Sigma Aldrich, cat: 435007) with MS 0.1330

converted to cellulose II. According to Coffey et al., (1995), cellulose II is obtained after mercerization, i.e., treatment with $\mathrm{NaOH}$. This conversion was also result in the broadening the distance between cellulose polymer molecules. The substitution to the cellulose polymers will be relatively easier than cellulose without alkalization treatment with $\mathrm{NaOH}$ (Fengel and Wegener, 1989).

The HPC (MS 0.1049) resulted from this work had lower crystallinity (24.39\%) than that of the commercial sample (MS 0.1330) did (27.27\%), this was shown in Fig. 6 . The different crystallinity levels may be resulted by the possibility of the different of cellulose source. The crystallinity of HPC with MS 0.1049 was lower than that of cellulose alkalized with $10 \% \mathrm{NaOH}$. This phenomenon was supposed to be the cleavage of the broadening hydrogen bonds due to hydroxypropyl substitution at the hydroxyl groups of cellulose. 


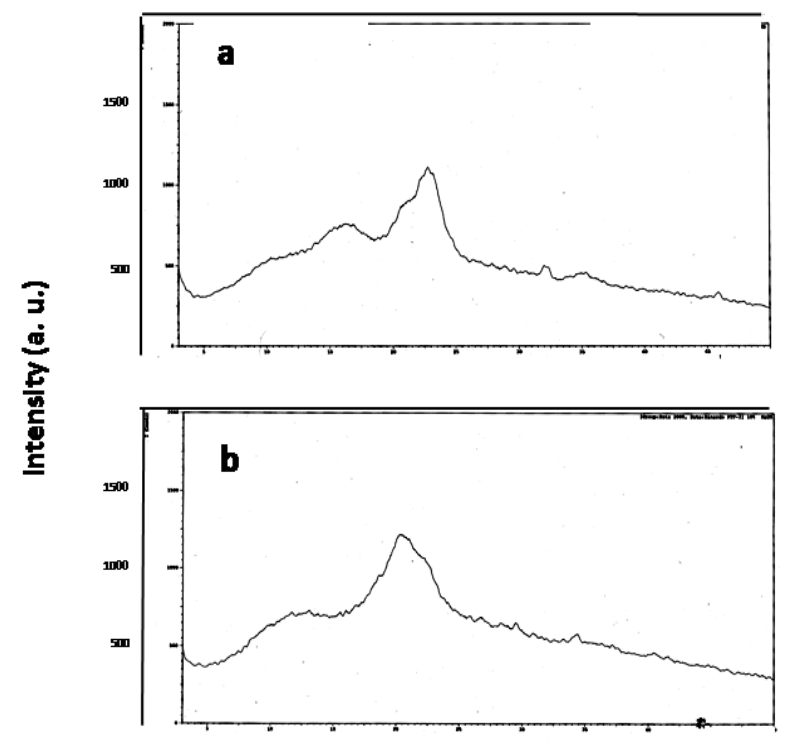

2Theta (Degree)

Fig . 5. X-Ray diffractogram of EFB cellulose. (a) Native EFB cellulose; (b) EFB cellulose after treated with $10 \% \mathrm{NaOH}$

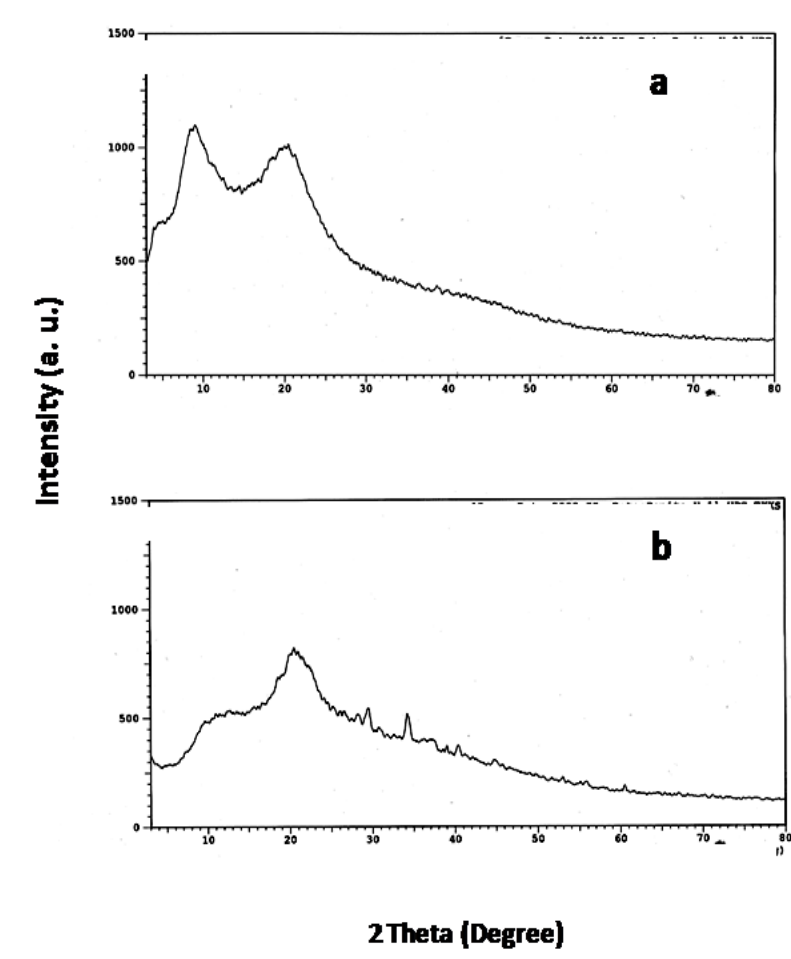

Fig. 6. X-Ray diffractogram of HPC. (a) commercial HPC from unknown source; (b) HPC from EFB cellulose with MS 0.1330

\section{Conclusion}

HPC could be synthesized from hydroxypropylation of EFB cellulose, although it had less characters than the commercial sample. The highest MS and viscosity value (0.1049 and
76.88 cps, respectively) was prepared by alkalization with $10 \% \quad \mathrm{NaOH}$ and hydroxypropylation with $\mathrm{PO} 1.4 \mathrm{ml} / \mathrm{g}$ cellulose, but the purity level was low (76.91\%). Therefore, further work is needed to gave higher the purity of HPC.

\section{Acknowledgements}

Author P. A. would like to thank Universitas Jenderal Soedirman - Purwokerto, Indonesia for giving the permission to further study at Study Program Magister of Estate Crop Technology, Faculty of Agricultural Technology, Universitas Gadjah Mada - Yogyakarta, Indonesia.

\section{References}

ASTM. 1994. Standard Test Methods for Sodium Carboxymethylcellulose. Philadelphia: ASTM Committeeon Standards. pp. 291298. (ASTM: D 1439-94).

Adinugraha, M.P., D.W, Marseno., and Haryadi. 2005. Synthesis and Characterization of Sodium Carboxymethylcellulose from Cavendish Banana Pseudo Stem (Musa cavendishii LAMBERT). Carbohyd. Polym. 62: 164-169.

Barai, B.K., R.S, Singhal., and P.R, Kulkarni. 1997. Optimization of A Process for Preparing Carboxymethyl cellulosa from Water Hyacinth (Eichornia crassipes). Carbohyd. Polym. 32: 229-231.

Coffey, D.G., D.A, Bell., and A, Henderson. 1995. Cellulose and Cellulose Derivatives In: Stephen, A. M. (editor). Food Polysaccharides and Their Applications. Marcel Dekker, Inc. New York.pp. 123-154.

Darnoko, 1992. The potency of utilization of lignocellulosic materials from palm oil fruits through bioconversion. Bulletin of Estate Crops. 2 (2): 85-87. (In Indonesian)

Dean, J.A. 1985. Lange's Handbook of Chemistry. 13ed. McGraw-Hill.

FAO \& WHO. 2001. Compendium of Food Additive Specifications. Paper 52. Addendumn 7.

Fengel, D. and Wegener, G. 1995. Wood: Chemistry, ultra-structure, reactions. First edition. Gadjah Mada University Press. Yogyakarta. (In Indonesian)

Foyle, T., L, Jennings., and P, Mulcahy. 2007. Compositional Analysis of Lignocellulosic materials: Evaluation of Methods Used for 
Sugar Analysis of Waste Paper and Straw. Bioresource Technol. 98: 3026-3036.

Hattori, K., E. Abe., T, Yoshida., and J.A, Cuculo. 2004. New Solvents for Cellulose II Ethylenediamine/thiocyanate Salt System. Polym. J. 36 (2): 123-130.

Ho, F. and D.W, Klosiewicz. 1980. Proton Nuclear Magnetic Resonance Spectrometry for Determination of Substituents and Their Distribution in Carboxymethylcellulose. Anal. Chem. 52 (6): 913-916.

Imeson, A. 1999. Thickening and Gelling Agents for Food. Second edition. An Aspen Publication. Maryland.pp. 60-83.

Maruyama, N. and $\mathrm{H}$, Umezawa. 2003. European Patent Specification. Great Britain.

Mezdour, S., Cuvelier, G., Cash, M.J., and Michon, C. 2006. Surface Rheological Properties of Hydroxypropylcellulose at Air-Water Interface. Food Hydrocolloids. 20: 1-6.

Rahman, S.H.A., J.P, Choudhury., A.L, Ahmad., and A.H, Kamaruddin. 2007. Optimization Studies on Acid Hydrolysis of Oil Palm Empty Fruit Bunch Fiber for Production of Xylose. Bioresource Technol. 98: 554-559.

Ramos, L.A., Frollini, E., and Heinze, T. 2005. Carboxymethylation of cellulose in the new solvent dimethyl sulfoxide/tetrabutylammonium fluoride. Carbohyd. Polym. 60: 259-267

Reuben, J. and H.T, Conner. 1983. Analysis of The Carbon-13 NMR Spectrum of Hydrolyzed O-(Carboxymethyl)cellulose: Monomer Composition and Substitution Patterns. Carbohyd. Res. 115 (1): 1-13.

Sastrohamidjojo, H. 2007. Spektroskopi. 3ed. Liberty. Yogyakarta.

Tezuka, Y., Y, Tsuchiya., and T, Shiomi. $1996 .{ }^{13} \mathrm{C}$ NMR determination of Substituent Distribution in Carboxymethylcellulose by Use of Its Peresterified Derivatives. Carbohyd. Res. 291: 99-108.

Wakida, T., M. Lee, S., J. Park., and A, Hayashi. 2002. Hot Mercerization of Cottons. Sen'i Gakkaishi. 58 (8): 304-307.

Yasar, F., H, Togrul., and N, Arslan. 2007. Flow properties of cellulose and carboxymethyl cellulose from orange peel. J. Food Eng. 81: 187-199. 